\title{
Decoration of Fibrin with Extracellular Chaperones
}

\author{
${ }^{1}$ Department of Hematology, Erasmus MC, University Medical Center \\ Rotterdam, Erasmus University Rotterdam, Rotterdam, The Netherlands \\ ${ }^{2}$ Clinical Chemistry Department, Amsterdam Neuroscience, \\ Amsterdam UMC, Amsterdam, The Netherlands \\ ${ }^{3}$ Psychiatry Department, Amsterdam Neuroscience, Amsterdam \\ UMC, Amsterdam, The Netherlands
}

Simone Talens ${ }^{1}$ Frank W. G. Leebeek ${ }^{1}$ Robert Veerhuis ${ }^{2,3}$ Dingeman C. Rijken ${ }^{1}$

\author{
Address for correspondence Dingeman C. Rijken, Department of \\ Hematology, Erasmus MC, University Medical Center Rotterdam, P.O. \\ Box 2040, 3000 CA Rotterdam, The Netherlands \\ (e-mail: d.rijken@erasmusmc.nl).
}

Thromb Haemost 2019;119:1624-1631.

\begin{abstract}
Keywords

- amyloid structure

- blood coagulation

- extracellular chaperones

- fibrin

- fibrinogen
\end{abstract}

Background Many proteins bind to fibrin during clot formation in plasma. We previously identified by mass spectrometry the most abundant proteins that noncovalently bind to fibrin clots. Several of these proteins (e.g., apolipoprotein J/clusterin, haptoglobin, $\alpha_{2}$-macroglobulin, $\alpha_{1}$-antitrypsin) can act as extracellular chaperones. Objective We hypothesize that clot-binding proteins may interact with fibrin as chaperones. The goal of this study is to test this hypothesis and to investigate the origin of the cross- $\beta$ or amyloid structures in fibrin clots, which are associated with protein unfolding.

Methods and Results A thioflavin T assay was used to detect cross- $\beta$ structures. A steadily increasing amount was measured in the fibrinogen fraction of plasma during heat stress, a standard treatment to induce unfolding of proteins. Heat-stressed plasma was clotted and clot-bound proteins were analyzed by sodium dodecyl sulfatepolyacrylamide gel electrophoresis. The results showed that the amounts of the clot-bound proteins were related to the duration of the heat stress. This indicates that cross- $\beta$ structures in unfolded fibrin(ogen) are involved in clot binding of the proteins, which supports our chaperone hypothesis. A contributing role of fibrin formation itself was studied by clotting purified fibrinogen with thrombin in the presence of thioflavin $T$. The fluorescence intensity increased in time in the presence of thrombin, but did not increase in its absence. This provides evidence for the generation of cross- $\beta$ structures during fibrin formation.

Conclusion Fibrin clots generated in plasma are decorated with extracellular chaperones. The binding of these chaperones involves cross- $\beta$ structures originating both from unfolded fibrinogen and from fibrin formation.

\section{Introduction}

Excessive blood coagulation results in the formation of thrombi. The main components of thrombi are cells such as platelets and erythrocytes and a fibrin network that is essential for the structural stability of the thrombus. ${ }^{1}$ Fibrinogen circulates at a plasma concentration of approximately $2.5 \mathrm{mg} / \mathrm{mL}$ (normal range $1.5-4.0 \mathrm{mg} / \mathrm{mL}$ ). When blood co-

received

March 26, 2019

accepted after revision

June 12, 2019 agulation is activated and thrombin is generated, fibrinogen is converted to fibrin monomers, which polymerize into protofibrils. These protofibrils aggregate laterally into fibers, which finally form the three-dimensional fibrin network of thrombi or of fibrin clots when plasma is clotted in vitro. ${ }^{1}$

Activated coagulation factor XIII (FXIIIa) is a transglutaminase that introduces several cross-links into the fibrin
DOI https://doi.org/

10.1055/s-0039-1693701. ISSN 0340-6245. (c) 2019 Georg Thieme Verlag KG
Stuttgart · New York
License terms

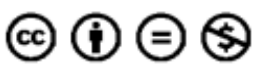


network, thereby stabilizing the clot. ${ }^{2}$ The action of FXIIIa also results in resistance to fibrinolysis. ${ }^{3}$ This is accomplished not only by intramolecular cross-links within fibrin, but also by intermolecular cross-links between fibrin and the fibrinolysis inhibitor $\alpha_{2}$-antiplasmin. FXIIIa is able to covalently cross-link many different plasma proteins to fibrin. A recent proteomic study identified 48 plasma proteins that are cross-linked to fibrin clots by FXIIIa. ${ }^{4}$

Plasma clots not only contain FXIIIa-mediated covalently bound plasma proteins, but also noncovalently bound proteins. The binding of these proteins may be involved in the regulation of hemostasis. ${ }^{5}$ Well-known examples are the binding of thrombin which limits thrombus formation ${ }^{6}$ and the binding of both plasminogen and tissue-type plasminogen activator (tPA) which strongly accelerates plasmin formation and thereby fibrinolysis. ${ }^{7}$ By using the proteomic analysis of washed plasma clots, we previously identified 18 abundant noncovalently clot-bound proteins. ${ }^{8}$ Using a slightly different approach, other investigators did not distinguish covalently and noncovalently clot-bound proteins and studied the whole clot proteome. ${ }^{9-11}$ The 18 noncovalently bound proteins that we identified, included several hemostatic proteins. However, the background of the binding of the majority of the noncovalently bound proteins in a clot remains unknown and this forms the main topic of the present study. We report that a significant number of these proteins are described in the literature as extracellular chaperones, a family of proteins in the extracellular fluids that share functional characteristics with intracellular chaperones. ${ }^{12}$ We provide evidence that they might be present in a fibrin clot on the basis of their chaperone activity. Chaperones bind to partially unfolded proteins, which may form cross- $\beta$ or amyloid-like protein structures. We studied the origin of these structures in the fibrin clot.

\section{Materials and Methods}

\section{Materials}

Human thrombin, urea, thiourea, and CHAPS were obtained from Sigma (St. Louis, Missouri, United States). Bovine milk $\alpha-, \beta-$, and $\mathrm{K}$-casein were also obtained from Sigma (product number C6780, C6905, and C0406, respectively). Aprotinin was obtained from BioVision (Milpitas, California, United States) and purified human fibrinogen (plasminogen-, von Willebrand factor-, and fibronectin-depleted) from Enzyme Research Laboratories (South Bend, Indiana, United States). Sodium dodecyl sulfate-polyacrylamide gel electrophoresis (SDS-PAGE) was calibrated with Precision Plus Protein Standards from Bio-Rad Laboratories (Hercules, California, United States). GelCode Blue Stain Reagent was from Thermo Scientific (Waltham, Massachusetts, United States) and Thioflavin T UltraPure Grade (ThT) from AnaSpec (Fremont, California, United States). The antibodies used for the $\alpha_{1}$-antitrypsin (A1AT)-fibrinogen enzyme-linked immunosorbent assay (ELISA) were from Affinity Biologicals (Ancaster, Ontario, Canada). Plasma was normal pooled platelet-poor plasma, prepared from citrated apheresis plasma (Sanquin blood bank, Rotterdam, The Netherlands) from five healthy donors.

\section{Heat-Induced Unfolding of Fibrinogen in Plasma}

Plasma was supplemented with sodium azide $(0.05 \%$ final concentration) and incubated in $1 \mathrm{~mL}$ aliquots for 0 , 1 , or 2 days at $37^{\circ}$ or $41^{\circ} \mathrm{C}$. Fibrinogen was isolated by two successive ammonium sulfate precipitations at $25 \%$ saturation and dissolved in $5 \mathrm{mM}$ sodium citrate. ${ }^{13}$ Unfolding of fibrinogen during the incubations at $37^{\circ} \mathrm{C}$ or $41^{\circ} \mathrm{C}$ resulting in cross- $\beta$ structures was assessed by mixing fibrinogen and ThT $(1 \mathrm{mg} / \mathrm{mL}$ and $0.1 \mathrm{mM}$ final concentrations, respectively) in $5 \mathrm{mM}$ sodium citrate. ThT fluorescence of $100 \mu \mathrm{L}$ aliquots was measured in black microtiter plates using a Victor $^{3}$ plate reader (PerkinElmer, Waltman, Massachusetts, United States) with excitation at $425 \mathrm{~nm}$ and emission at $486 \mathrm{~nm}$ and expressed in arbitrary units (a.u.). All measurements were done at $20^{\circ} \mathrm{C}$ for 0.1 second at a continuous wave lamp intensity of 10,000 .

\section{Clot-Bound Proteins after Heat Treatment of Plasma}

Plasma was supplemented with sodium azide $(0.05 \%$ final concentration) and incubated for 0,1 , or 2 days at $41^{\circ} \mathrm{C}$. Next, calcium chloride (20 mM final concentration), thrombin (1 $\mathrm{NIH} \mathrm{U/mL} \mathrm{final} \mathrm{concentration),} \mathrm{and} \mathrm{aprotinin} \mathrm{(100} \mathrm{KIU/}$ $\mathrm{mL}$ final concentration) were added to each plasma sample $(500 \mu \mathrm{L})$ to induce clot formation. ${ }^{8}$ After 2 hours of incubation at room temperature, the clots were extensively washed by perfusing them overnight with $10 \mathrm{~mL}$ Tris-buffered saline (50 mM Tris- $\mathrm{HCl}, 100 \mathrm{mM} \mathrm{NaCl}, \mathrm{pH}$ 7.4) containing aprotinin $(100 \mathrm{KIU} / \mathrm{mL})$ at $4^{\circ} \mathrm{C}$. The clots were compacted by centrifugation, washed with deionized water, and noncovalently clot-bound proteins were extracted with $30 \mu \mathrm{L}$ rehydration buffer ( 7 M urea, 2 M thiourea, 4\% [w/v] CHAPS) for 1 hour at room temperature. The extracts were mixed with SDS-PAGE sample buffer containing $\beta$-mercaptoethanol, incubated for 5 minutes at $95^{\circ} \mathrm{C}$ and analyzed using SDS-PAGE (Laemmli system, $12 \%$ gel). Proteins were stained using GelCode Blue Stain Reagent according to the manufacturer's instructions. The proteins in the main bands were identified by matrixassisted laser desorption/ionization time-of-flight (MALDIToF), as described previously. ${ }^{8}$

\section{Heat-Induced Formation of A1AT-Fibrinogen Complex in Plasma}

Plasma was supplemented with sodium azide $(0.05 \%$ final concentration) and incubated in $1 \mathrm{~mL}$ aliquots for $0,0.25,1$, or 2 days at $37^{\circ} \mathrm{C}$ or $41^{\circ} \mathrm{C}$. Fibrinogen was isolated by two successive ammonium sulfate precipitations at $25 \%$ saturation and dissolved in $5 \mathrm{mM}$ sodium citrate. ${ }^{13}$ A1AT-fibrinogen complex concentration in the fibrinogen samples was determined using a sandwich ELISA consisting of a capture antibody against A1AT and a horseradish peroxidase-labeled detecting antibody against fibrinogen, as described previously. ${ }^{14}$

\section{Generation of Cross- $\beta$ Structures during Coagulation}

Generation of cross- $\beta$ structures during coagulation was tested by incubating $3 \mathrm{mg} / \mathrm{mL}$ commercially available fibrinogen in black microtiter plates $(150 \mu \mathrm{L} /$ well $)$ with $7.5 \mathrm{mM}$ calcium chloride and $0.25 \mathrm{NIH} \mathrm{U} / \mathrm{mL}$ human thrombin in $50 \mathrm{mM}$ Tris$\mathrm{HCl}$, pH 8.0 containing $100 \mathrm{mM} \mathrm{NaCl}$, in the presence of $0.1 \mathrm{mM}$ 
ThT. Fluorescence in the samples was measured as described above, both before and repeatedly after the induction of coagulation with thrombin for 60 minutes at $20^{\circ} \mathrm{C}$. Fibrinogen samples without added thrombin were measured as control. Clot formation of similar samples was measured as turbidity (optical density [OD] at $405 \mathrm{~nm}$ ) in parallel experiments.

\section{Effect of Casein Proteins on Fibrin Polymerization}

The effects of the extracellular chaperones $\alpha$-, $\beta$-, and $\mathrm{K}$-casein on fibrin polymerization were tested in microtiter plates as described by Carter et al ${ }^{15}$ with slight modifications: $100 \mu \mathrm{L}$ diluted plasma with $\alpha-$, $\beta$-, or $\mathrm{K}$-casein in assay buffer $(50 \mathrm{mM}$ Tris- $\mathrm{HCl}, \mathrm{pH} 7.4$, containing $100 \mathrm{mM} \mathrm{NaCl}$ and $1 \mathrm{mg} / \mathrm{mL}$ bovine serum albumin) was mixed in duplicate with $50 \mu \mathrm{L}$ thrombin and calcium chloride in assay buffer and covered with $50 \mu \mathrm{L}$ paraffin oil. Clot formation was monitored by measuring the OD at $405 \mathrm{~nm}$ every 35 seconds for 60 minutes at room temperature in a microplate reader. The final concentrations in the clot were $11.1 \%(\mathrm{v} / \mathrm{v})$ plasma, $0,5,10,20$, or $30 \mu \mathrm{M}$ casein protein, $0.001 \mathrm{NIH} \mathrm{U/mL} \mathrm{thrombin,} \mathrm{and} 2.5 \mathrm{mM}$ calcium chloride. This corresponds to a molar ratio of casein and fibrinogen of approximately $0,5,10,20$, or 30 , respectively.

\section{Results}

When plasma is clotted, several proteins are noncovalently bound to the fibrin clot matrix. - Fig. 1 shows two-dimensional (2D) gel electrophoresis of these proteins, along with the identification of the most abundant ones, as we published previously. ${ }^{8}$ The proteins identified show up as ladders or row of spots, which is common for plasma proteins. The presence of these proteins in a fibrin clot, apart from the presence of the fibrin-binding hemostatic proteins plasminogen, FXIII-A subunit, thrombin, and possibly carboxypeptidase N (CPN), is not well understood. However, - Fig. 1 shows that the majority of the apparently nonhemostatic fibrin clot-bound proteins consists of proteins that are classified by Wyatt et al ${ }^{12}$ as extracellular chaperones or at least as extracellular proteins with chaperone activity (white printed protein names).These proteins include apolipoprotein $\mathrm{J}(\mathrm{ApoJ})$, also known as clusterin, haptoglobin, $\alpha_{2}$-macroglobulin $(\alpha 2 \mathrm{M})$, ApoE, ApoAI, albumin, serum amyloid $\mathrm{P}$, and A1AT.

Extracellular chaperones bind to unfolded proteins, which can aggregate into soluble oligomers and subsequently into amorphous material or into fibrillary material both containing cross- $\beta$ structures. ${ }^{12}$ To test our hypothesis that the nonhemostatic clot-bound proteins bind to a fibrin clot because of their chaperone activities, plasma was incubated at elevated temperature to increase the content of unfolded fibrinogen, after which the plasma was clotted and clots were analyzed for the presence of clot-bound proteins. In pilot experiments, plasma was incubated at varying temperatures, fibrinogen was isolated, and unfolding of fibrinogen was assessed with ThT, a fairly specific reagent for cross- $\beta$ structures. $^{16,17}$ - Fig. 2 shows that fibrinogen isolated from control plasma (incubation time: 0 days) produced already a significant ThT fluorescence intensity of approximately 1,400 a.u. pointing to the presence of unfolded fibrinogen in the starting material. Incubation of plasma for 2 days at $37^{\circ}$ $\mathrm{C}$ hardly increased the ThT fluorescence. However, incubation of plasma at $41^{\circ} \mathrm{C}$ resulted in a steadily increasing ThT fluorescence, indicating a steadily increasing amount of unfolded fibrinogen. Incubation of plasma at $45^{\circ} \mathrm{C}$ resulted in an even higher fluorescence, but some protein precipitation occurred in these samples.

Therefore, a temperature of $41^{\circ} \mathrm{C}$ was selected and plasma was incubated for 0,1 , or 2 days and clotted with calcium and thrombin. Clots were extensively washed and clot-bound proteins were extracted and analyzed by SDS-PAGE. Onedimensional SDS-PAGE was chosen rather than 2D electrophoresis used in - Fig. 1 to allow a better comparison of the amounts of clot-bound proteins after varying incubation periods of the plasma (-Fig. 3). The clot prepared from plasma incubated for 0 days provided a protein sample that was similar to the protein sample analyzed by 2D gel electrophoresis in -Fig. 1. Indeed, the protein bands

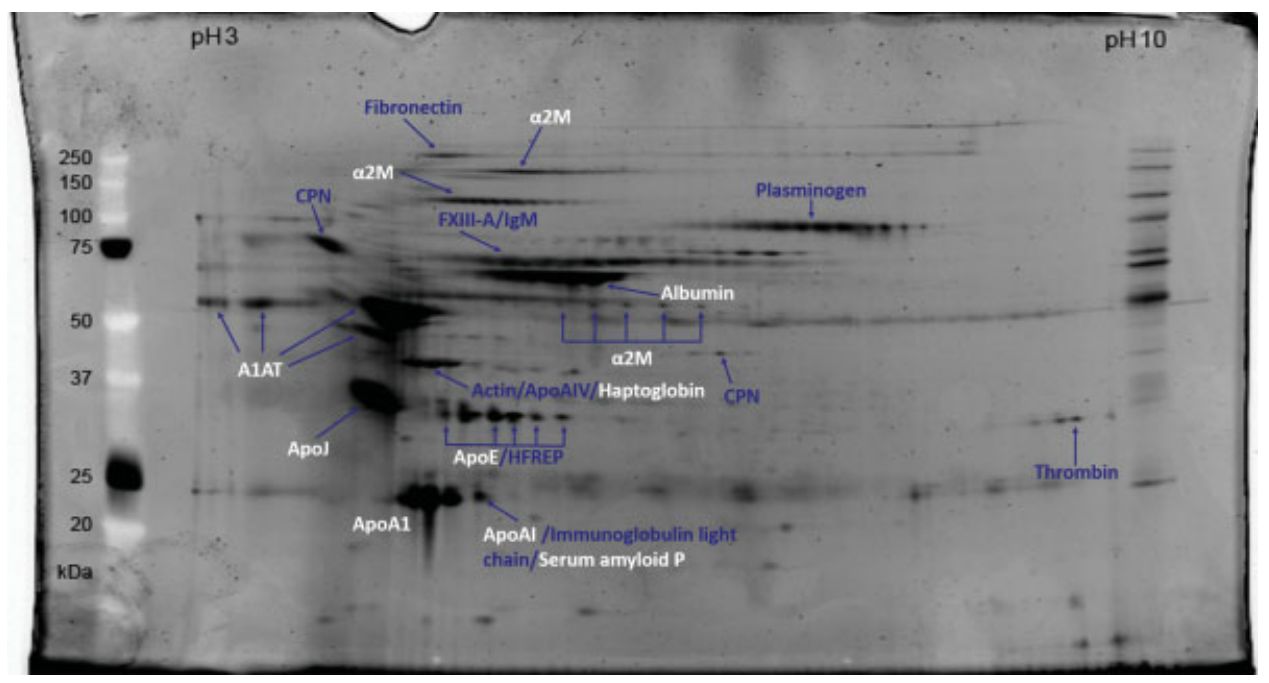

Fig. 1 Plasma-clot bound proteins after separation with two-dimensional (2D) gel electrophoresis and identification by mass spectrometry. The figure is adapted from Talens et al, $2012 .^{8}$ The majority of the proteins, indicated in white, are described as having chaperone activity. ${ }^{12}$ 


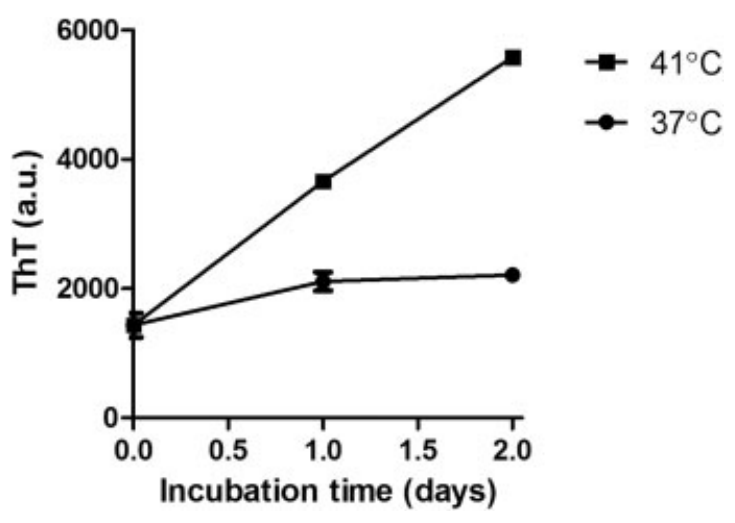

Fig. 2 Heat-induced unfolding of fibrinogen in plasma. Platelet-poor citrated plasma was stressed by incubation at $37^{\circ} \mathrm{C}$ or $41^{\circ} \mathrm{C}$ for 0,1 , or 2 days. After the incubation fibrinogen was isolated from the plasma samples by ammonium sulfate precipitation. Cross- $\beta$ structures in the fibrinogen samples were measured by thioflavin T (ThT) fluorescence. The background of the ThT signal (2,023 arbitrary units [a.u.]) was subtracted from all samples. Mean values (with range) of duplicate measurements are shown; the error bars are in some cases too small to be visible.

in - Fig. 3 ( 0 days incubation) matched well with the protein spots in - Fig. 1. The clots prepared from plasma incubated for 1 or 2 days yielded the same protein bands as the clot prepared from nonincubated plasma but with a gradually

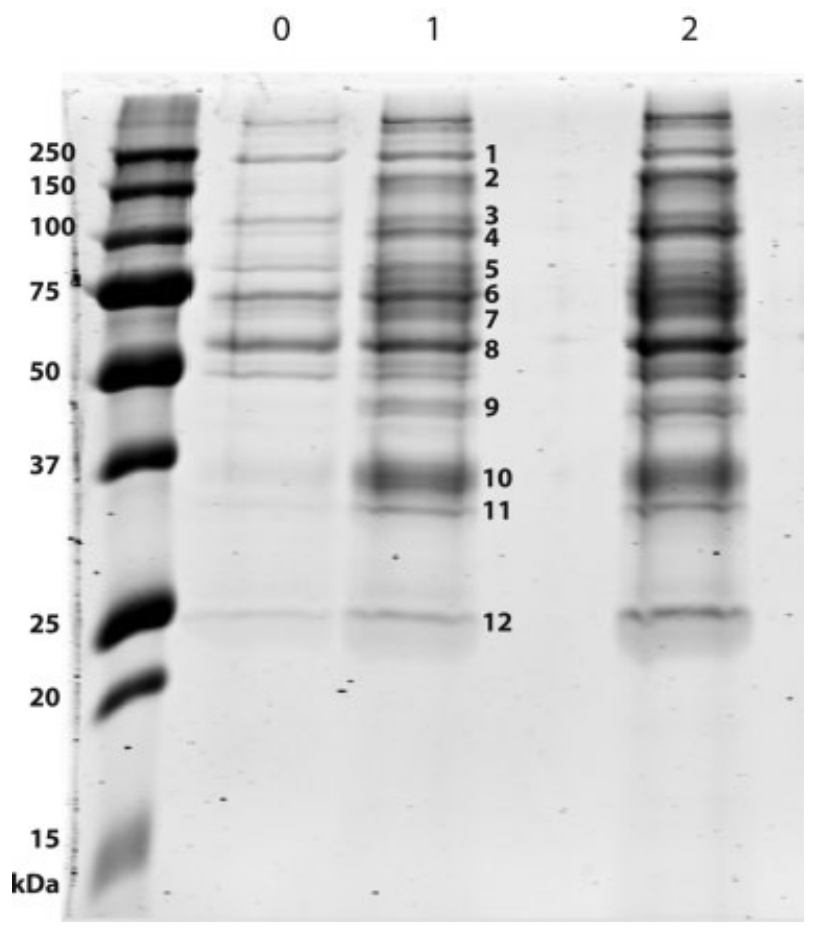

Fig. 3 Sodium dodecyl sulfate-polyacrylamide gel electrophoresis (SDS-PAGE) of clot-bound proteins after heat treatment of plasma. Platelet-poor citrated plasma was incubated for 0,1 , or 2 days at $41^{\circ} \mathrm{C}$ and clots were prepared by adding calcium chloride, thrombin, and aprotinin. Unbound proteins were washed away, bound proteins were extracted, analyzed using SDS-PAGE, and stained with GelCode Blue Stain Reagent. The left lane shows the protein markers. The identity of the individual protein bands $1-12$ in the other three lanes is shown in

-Table 1. increasing intensity. This result strongly suggests that unfolded fibrin(ogen) is involved in the binding of the proteins, both before and after the incubation of plasma at $41^{\circ} \mathrm{C}$, which supports our chaperone hypothesis.

The identity of the protein bands in - Fig. 3 was partially derived from MALDI-ToF analysis and partially by comparing the migration of the bands with the vertical migration of the spots, shown in - Fig. 1 ( - Table 1). In most bands extracellular chaperones were identified, except in band 1 (fibronectin), band 4 (plasminogen), band 5 (CPN, polypeptide 2 ), and band 6 (FXIII-A). The intensity of the latter bands also increased with the incubation time of plasma. This may suggest that the binding of these proteins to fibrin might also involve unfolded fibrin(ogen)/cross- $\beta$ structures in the fibrin network.

The results of the experiment shown in - Fig. 3 suggest that the chaperone proteins bind to unfolded fibrinogen and remain associated during fibrin formation. The binding of the most abundant clot-binding protein $\mathrm{A}^{\mathrm{A}} \mathrm{AT}^{14}$ to unfolded fibrinogen was also assessed in plasma (without clot formation) with an ELISA specifically detecting A1AT-fibrinogen complexes. - Fig. 4 shows that nonincubated plasma contained approximately $4 \mu \mathrm{g} / \mathrm{mL}$ A1AT-fibrinogen complex, which is in line with our previous work. ${ }^{14}$ This concentration hardly increased during the incubation of plasma for 2 days at $37^{\circ} \mathrm{C}$. The complex concentration increased strongly during incubation at $41^{\circ} \mathrm{C}$, in line with a significant rate of unfolding of

Table 1 Identity of protein bands of SDS-PAGE of clot-bound proteins, shown in - Fig. 3

\begin{tabular}{|l|l|}
\hline Band no. & Protein \\
\hline 1 & Fibronectin \\
\hline 2 & $\alpha_{2}$-Macroglobulin* \\
\hline 3 & $\alpha_{2}$-Macroglobulin \\
\hline 4 & Plasminogen* \\
\hline 5 & Carboxypeptidase N, polypeptide 2 \\
\hline 6 & Coagulation factor XIII, A1 polypeptide \\
\hline 7 & Albumin* \\
\hline 8 & $\alpha_{1}$-Antitrypsin* \\
\hline 9 & $\begin{array}{l}\text { Actin, gamma 1 } \\
\text { Apolipoprotein AIV } \\
\text { Haptoglobin }\end{array}$ \\
\hline 10 & $\begin{array}{l}\text { Apolipoprotein J (clusterin) } \\
\alpha_{1} \text {-Antitrypsin }\end{array}$ \\
\hline 11 & $\begin{array}{l}\text { Apolipoprotein E } \\
\text { HFREP-1 }\end{array}$ \\
\hline 12 & $\begin{array}{l}\text { Apolipoprotein Al } \\
\text { Immunoglobulin light chain } \\
\text { Serum amyloid P }\end{array}$ \\
\hline
\end{tabular}

Abbreviations: HFREP-1, hepatocyte-derived fibrinogen-related protein1; SDS-PAGE, sodium dodecyl sulfate-polyacrylamide gel electrophoresis.

Note: The proteins labeled with a star were identified by matrix-assisted laser desorption/ionization time-of-flight (MALDI-ToF). The other proteins were identified by comparing the migration of the bands with the vertical migration of the spots, shown in - Fig. 1 . 


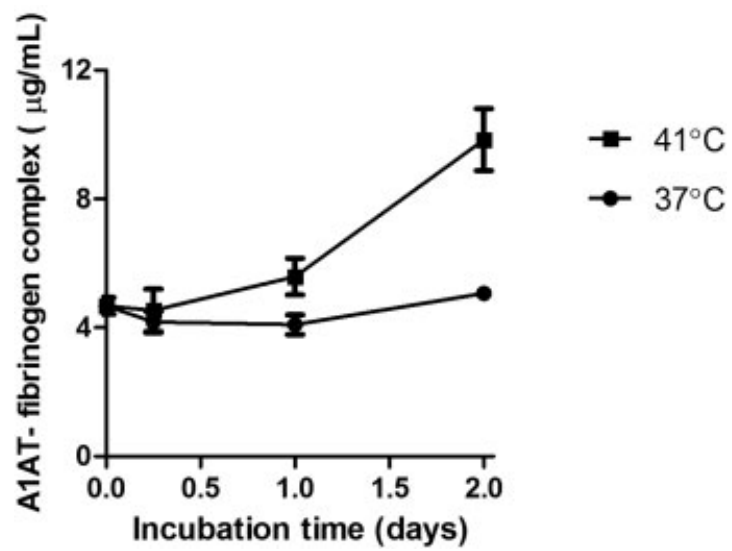

Fig. 4 Heat-induced formation of $\alpha_{1}$-antitrypsin (A1AT)-fibrinogen complex in plasma. Platelet-poor citrated plasma was stressed by incubation at $37^{\circ} \mathrm{C}$ or $41^{\circ} \mathrm{C}$ for $0,0.25$, 1 , or 2 days. After the incubation fibrinogen was isolated from the plasma samples by ammonium sulfate precipitation. The amounts of A1AT-fibrinogen complex in the fibrinogen samples were determined using an enzymelinked immunosorbent assay (ELISA). Mean values ( \pm standard deviation [SD]) of five measurements are shown.

fibrinogen at $41^{\circ} \mathrm{C}$, as observed in - Fig. 2. This experiment indicates that clotting is not required for the formation of a complex between a chaperone and fibrin(ogen).

Although clot formation is not crucial for chaperone binding, a contributing role for clotting might be possible if fibrin formation itself is associated with the generation of cross- $\beta$ structures. This was studied by clotting commercially available purified fibrinogen in calcium chloride with thrombin in the presence of ThT. -Fig. 5 shows that $3 \mathrm{mg} / \mathrm{mL}$ fibrinogen already produced a significant ThT fluorescence intensity of approximately 4,000 a.u., which is in line with a positive ThT signal produced by freshly isolated fibrinogen from plasma in -Fig. 2. The fluorescence intensity increased in time to approximately 7,000 a.u. in the presence of thrombin, but did not increase in the absence of thrombin (-Fig. 5A). The increase in fluorescence signal paralleled the increase in turbidity associated with clot formation ( - Fig. 5B), thus providing evidence for the generation of cross- $\beta$ structures during fibrin formation. The overall results indicate that the clot binding of chaperone proteins could involve cross- $\beta$ structures originating from both unfolded fibrinogen and from the conversion of fibrinogen into fibrin.

A potential functional effect of clot binding of chaperone proteins was studied with casein proteins, which have been described as extracellular chaperone molecules. The lag time of plasma clot formation of approximately 12.6 minutes increased dose-dependently to $26.0,19.5$, and 42.5 minutes in the presence of $30 \mu \mathrm{M} \alpha$-casein, $\beta$-casein, and $\mathrm{k}$-casein, respectively. - Fig. 6 shows the clotting profiles in the presence of $\mathrm{k}$-casein. The results thus indicated that the casein proteins delayed fibrin polymerization during clotting of diluted plasma.

\section{Discussion}

This study shows that fibrin clots generated from plasma are decorated with the proteins which we identified as extracel-

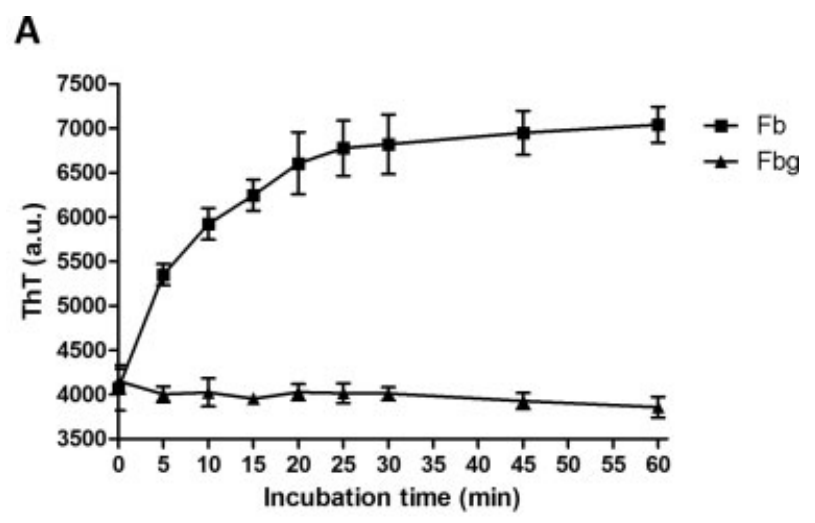

B

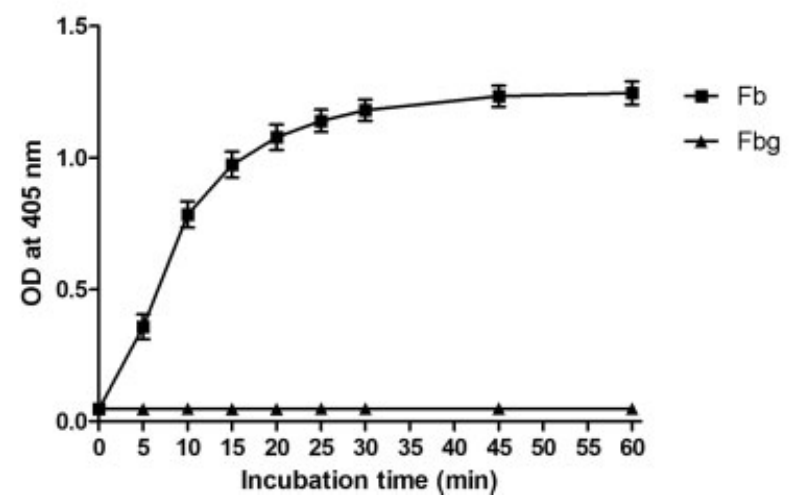

Fig. 5 Generation of cross- $\beta$ structures during coagulation. (A) The thioflavin T (ThT) fluorescence of a solution containing fibrinogen, calcium chloride, and ThT, with (Fb) or without thrombin (Fbg) was measured at the time points indicated. The background of the ThT signal (2,759 arbitrary units [a.u.]) was subtracted from all samples. (B) The turbidity of similar samples was measured as optical density (OD) at $405 \mathrm{~nm}$ in parallel experiments. Mean ( \pm standard deviation [SD]) values are shown ( $n=3$, in duplicate).

lular chaperones. Extracellular chaperones bind to partially unfolded protein structures. These structures are provided in a fibrin clot by small amounts of unfolded fibrinogen in the plasma. In addition, they are generated during the conversion of fibrinogen to fibrin. The presence of extracellular

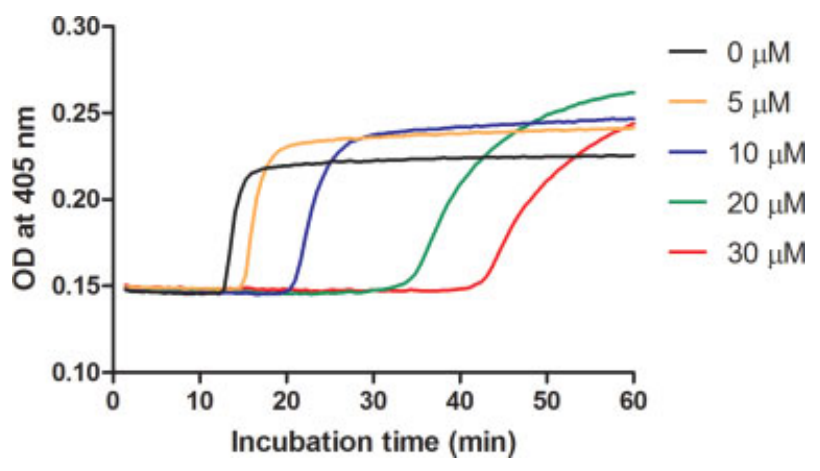

Fig. 6 Inhibition of fibrin polymerization by к-casein. Ninefold diluted plasma was clotted with thrombin and calcium chloride in the presence of $0-30 \mu \mathrm{M}$ k-casein. Fibrin polymerization was visualized by measuring the turbidity as optical density (OD) at $405 \mathrm{~nm}$ at room temperature. 
chaperones in clots and thrombi is a new feature with potential implications for thrombotic diseases and bleeding disorders.

\section{Extracellular Chaperones}

In a previous study, we described that extensively washed plasma clots contain many noncovalently bound plasma proteins and we identified the most abundant ones by mass spectrometry. ${ }^{8}$ These proteins included several hemostatic proteins. However, the majority of the proteins had no known hemostatic function and the cause of the presence of these proteins remained unclear. We noted the presence of several proteins originating from high-density lipoproteins and postulated that these lipoproteins may play a role in hemostasis. Up to now, no information is available about the binding of high-density lipoproteins to fibrin clots. The main discovery of the present study is that most of the apparently nonhemostatic proteins noncovalently bound to fibrin clots are described in the literature as extracellular chaperones. ${ }^{12}$

Molecular chaperones interact with other proteins to stabilize them or to help them acquire their functionally active conformation, without being present in its final structure. ${ }^{18}$ Intracellular chaperones have been known for a long time and many of them are heat shock proteins. Knowledge of extracellular chaperones has lagged well behind. However, in recent years it has become clear that there is a family of abundant proteins in the extracellular fluids that share functional characteristics with the intracellular small heat shock proteins. They bind to unfolded proteins in the extracellular fluids, inhibit their aggregation, and promote clearance from extracellular spaces. ${ }^{12}$ Therefore, they may protect us from diseases that are characterized by extracellular protein deposition such as Alzheimer's disease, prion diseases, macular degeneration, and type 2 diabetes. The main chaperones involved in these diseases and actually colocalized in the protein deposits are clusterin, haptoglobin, and $\alpha 2 \mathrm{M} .{ }^{12}$

After the discovery in the present study that most of the apparently nonhemostatic proteins in fibrin clots are extracellular chaperones, we next investigated whether they are localized in the clots as a result of their chaperone activities. Heat is a well-known inducer of protein unfolding and cross$\beta$ structures in the laboratory. It thermally destabilizes the tertiary and secondary protein structure leading to protein unfolding and aggregation and mimics the prolonged effects of aging and shear stress on plasma proteins. Heat-induced unfolding of extracellular proteins thus differs from intracellular unfolding/misfolding during protein maturation. ${ }^{12}$ We first tested which temperature is required to induce an increase of cross- $\beta$ structures in fibrinogen and found that incubation of plasma for 2 days at $41^{\circ} \mathrm{C}$ resulted in a significant increase of these structures (-Fig. 2). We then found that these conditions indeed generated a strong increase in the amount of clot-bound proteins (-Fig. 3 ).

It should be noted that the majority but not all of the clotbound proteins have been described as chaperones. One explanation is that the nonchaperone proteins might be incorporated into fibrin clots as a constituent of a larger particle containing a strong chaperone, such as a clusterin- containing high-density lipoprotein particle. The presence of apoAIV could be explained in this manner.

Our finding that certain proteins with reported but not yet confirmed chaperone-like activity are present in fibrin clots, provides additional evidence that they can be classified as extracellular chaperones. One example is A1AT. Although its chaperone identity has still to be proven, ${ }^{12} \mathrm{~A} 1 \mathrm{AT}$ is the most abundant and remarkably strongly bound plasma protein in a fibrin clot. ${ }^{14}$

It is known that the hemostatic proteins tPA and plasminogen bind to fibrin. Because tPA is present in plasma at low concentrations ( $\mathrm{ng} / \mathrm{mL}$ range), this protein was not detected in our proteomic studies, but it is well known that tPA, and possibly also plasminogen, interacts with denatured proteins. ${ }^{19,20}$ tPA has been characterized as a multiligand cross$\beta$ structure receptor. ${ }^{21}$ Its binding to amyloid fibrils is not solely dependent on the finger domain or on the lysine binding site in kringle 2 domain, but involves multiple domains of tPA. ${ }^{22}$ The plasminogen activator may play a role in the removal of cross- $\beta$ structure-containing (improperly folded) proteins via plasminmediated proteolysis. Thus, tPA shares functional properties with extracellular chaperones by promoting clearance of unfolded proteins from extracellular spaces. The plasminogen activation system may work synergistically with other chaperones such as clusterin and $\alpha 2 \mathrm{M}$, which are involved in the neutralization and clearance of soluble and potentially cytotoxic fragments of protein aggregates. ${ }^{23}$

It is interesting that a $420-\mathrm{kDa}$ isoform of fibrinogen (fibrinogen-420), but not the predominant $340 \mathrm{kDa}$ form, shows chaperone-like activity. ${ }^{24}$ This holds true, in particular, for the additional 236-residue carboxyl terminus globular domain of fibrinogen-420 $\left(\alpha_{\mathrm{E}} \mathrm{C}\right)$ in isolated form, which might be produced in vivo by proteolysis of fibrinogen- 420 . However, the plasma concentrations of fibrinogen-420 (1\% of the total fibrinogen concentration) and its degradation product $\alpha_{E} C$ (a small fraction of fibrinogen-420) are low, much lower than the plasma concentrations of the known extracellular chaperones and they were therefore not detected in the present study.

\section{Cross- $\beta$ Structures}

What is the origin of cross- $\beta$ structures in fibrin clots? Our experiments with heat-stressed plasma indicate that unfolded fibrinogen is involved in protein binding to clots from this plasma and suggest that in untreated plasma unfolded fibrinogen could also play a role. Indeed, fibrinogen from unheated plasma showed already significant ThT fluorescence (-Fig. 2). Although this fluorescence could, in theory, be ascribed to some nonspecific binding of $\mathrm{ThT},{ }^{17}$ the presence of real cross- $\beta$ structures is supported by the presence of A1AT-fibrinogen complexes in unheated plasma (-Fig. 4). These observations could possibly be explained by in vitro handling of blood and plasma. However, unfolded fibrinogen may already occur in the circulation. The in vivo half-life of fibrinogen is approximately 4 days. Although - Fig. 4 shows that during incubation of plasma for 2 days at $37^{\circ} \mathrm{C}$ no significant amounts of A1AT-fibrinogen complexes are generated, additional experiments reveal that detectable 
amounts are generated during incubation for 4 days at $37^{\circ} \mathrm{C}$ (data not shown). Moreover, additional stress factors are present in the circulation such as shear and oxidation. It has been shown that shear stress induces the formation of clusterin-fibrinogen complexes in plasma ${ }^{25}$ and that oxidation induces the formation of $\alpha 2 \mathrm{M}$-fibrinogen complexes. ${ }^{26}$ In this connection, it is interesting to note that fibrinogen is much more susceptible to oxidative modification than other major plasma proteins. ${ }^{27}$

In addition to unfolded fibrinogen in plasma, fibrin formation itself might be associated with the generation of cross- $\beta$ structures. This was presented in an interesting review article by Gebbink, ${ }^{28}$ but experimental details are missing. Longstaff et $\mathrm{al}^{29}$ observed cross- $\beta$ structures predominantly in fibrin agglomerates that arise on the surface of a clot during external lysis. ${ }^{30}$ Other investigators collected evidence that coagulation is normally not associated with $\beta$-sheet formation, but that clotting of plasma from patients with various inflammatory diseases clearly results in fibrin with amyloid properties. ${ }^{31,32}$ Because of these different results and views, we studied this topic in detail and clotted purified fibrinogen in the presence of ThT ( - Fig. 5). A generation of cross- $\beta$ structures was observed in parallel with the formation of a fibrin network, detected as turbidity. This is in line with the original observations by Hudry-Clergeon et $\mathrm{al}^{33}$ that (cross-) $\beta$ sheet structures increased significantly from approximately $10 \%$ in fibrinogen to $20 \%$ in fine clots with thin fibers or $30 \%$ in coarse clots with thick fibers. The difference between fine and coarse clot observed by these authors indicates that the cross- $\beta$ structures depend on the lateral aggregation of protofibrils. ${ }^{33}$ More recent work indeed suggests that polymerization of $\alpha \mathrm{C}$ domains of fibrin involves the formation of $\beta$-sheets. ${ }^{34}$ Taken together, the data supports the notion that normal fibrin formation is associated with the formation of cross- $\beta$ structures. ${ }^{28}$ This does not exclude the possibility that additional cross- $\beta$ structures could be formed during thrombus formation under inflammatory conditions $^{31,32}$ or during external lysis of thrombi. ${ }^{29}$ of interest is that deformation of fibrin clots during stretching or compression is associated with a $\alpha$-helix to $\beta$-sheet transition and formation of cross- $\beta$ structures. ${ }^{35}$ This transition occurs in the coiled-coil regions of a fibrin molecule.

The binding sites in a fibrin clot for chaperone proteins could be provided by both unfolded fibrinogen and structures generated during fibrin formation. In terms of ThT fluorescence intensity under the experimental conditions of $\mathbf{- F i g . ~ 5 , ~ t h e ~ r e s p e c t i v e ~ c o n t r i b u t i o n s ~ a r e ~ a p p r o x i m a t e l y ~}$ 4,000 and 3,000 a.u., which means of the same order of magnitude. It is, however, still uncertain whether the two types of cross- $\beta$ structures are similarly involved in chaperone binding. Until now, we (in - Fig. 4) and others ${ }^{25,26}$ have only proven that unfolded fibrinogen in plasma does bind extracellular chaperones.

\section{Potential Implications}

This study explains the strong binding of several plasma proteins to fibrin clots by their identification as extracellular chaperones. The amounts of the bound chaperones are substoichiometric with respect to fibrin. For instance, we previously estimated that the amount of A1AT bound to normal fibrin clots was $0.25 \mu \mathrm{g}$ A1AT per mg of fibrin, ${ }^{14}$ which corresponds to a molar ratio of 1:700. The molar ratio of all bound chaperones together will, however, be several times greater. In addition, the stoichiometry might increase in diseases with elevated concentrations of extracellular chaperones in the circulation or elevated contents of cross- $\beta$ structures in clots. Although the amounts of clot-bound chaperones are low, they are of the same order of magnitude as the amounts of clotbound hemostatic proteins with a regulatory effect such as plasminogen, FXIII-A, and thrombin (-Fig. 1), suggesting that the chaperones could possibly also play a regulatory role in thrombosis and hemostasis. Potential mechanisms include the inhibition of fibrin polymerization and the promotion of the clearance of unfolded fibrin(ogen) from the circulation. We tested the antipolymerizing effect of casein proteins, readily available proteins that have been recognized as extracellular chaperones. These proteins include $\alpha$-casein ${ }^{36,37}$ as well as $\beta$ casein and $\mathrm{k}$-casein. ${ }^{38}$ All casein proteins proved to inhibit fibrin polymerization by significantly increasing the lag time of clot formation (-Fig. 6). Future studies should show how effective the extracellular chaperones from plasma inhibit fibrin polymerization and reveal anticoagulant activity. It is interesting that extracellular chaperones, such as high-density lipoprotein and its major ApoAI, might also be antithrombotic by preventing von Willebrand factor self-association and subsequent platelet adhesion. ${ }^{39}$

\section{What is known about this topic?}

- Plasma clots contain many fibrin-bound proteins.

- Fibrin-bound proteins include several hemostatic proteins, but also apparently nonhemostatic proteins.

\section{What does this paper add?}

- The most abundant fibrin-binding proteins are identified as extracellular chaperones. Extracellular chaperones usually bind to partially unfolded proteins, which may form cross- $\beta$ (amyloid-like) structures.

- Cross- $\beta$ (amyloid-like) structures in fibrin clots originate both from misfolded/unfolded fibrinogen in plasma and from fibrin formation.

\section{Authors' Contributions}

S.T. designed the research, performed the laboratory experiments, analyzed and interpreted data, and wrote the manuscript; F.W.G.L. designed the research and interpreted data; R.V. provided critical support about amyloid structures and for the experiments with thioflavin T; D.C. R. designed the research, analyzed and interpreted data, and wrote the manuscript. All authors critically reviewed the manuscript and gave their consent. 


\section{Conflict of Interest}

None declared.

\section{Acknowledgment}

The authors thank Mrs. Joyce J.M.C. Malfliet for the performance of the ELISAs of the A1AT-fibrinogen complex.

\section{References}

1 Weisel JW. Fibrinogen and fibrin. Adv Protein Chem 2005; 70:247-299

2 Muszbek L, Bereczky Z, Bagoly Z, Komáromi I, Katona É. Factor XIII: a coagulation factor with multiple plasmatic and cellular functions. Physiol Rev 2011;91(03):931-972

3 Rijken DC, Uitte de Willige S. Inhibition of fibrinolysis by coagulation factor XIII. BioMed Res Int 2017;2017:1209676

4 Nikolajsen CL, Dyrlund TF, Poulsen ET, Enghild JJ, Scavenius C. Coagulation factor XIIIa substrates in human plasma: identification and incorporation into the clot. J Biol Chem 2014;289(10): 6526-6534

5 Weisel JW, Litvinov RI. Fibrin formation, structure and properties. Subcell Biochem 2017;82:405-456

6 Liu CY, Nossel HL, Kaplan KL. The binding of thrombin by fibrin. J Biol Chem 1979;254(20):10421-10425

7 Hoylaerts M, Rijken DC, Lijnen HR, Collen D. Kinetics of the activation of plasminogen by human tissue plasminogen activator. Role of fibrin. J Biol Chem 1982;257(06):2912-2919

8 Talens S, Leebeek FW, Demmers JA, Rijken DC. Identification of fibrin clot-bound plasma proteins. PLoS One 2012;7(08):e41966

9 Howes JM, Richardson VR, Smith KA, et al. Complement C3 is a novel plasma clot component with anti-fibrinolytic properties. Diab Vasc Dis Res 2012;9(03):216-225

10 Suski M, Siudut J, Ząbczyk M, Korbut R, Olszanecki R, Undas A. Shotgun analysis of plasma fibrin clot-bound proteins in patients with acute myocardial infarction. Thromb Res 2015;135(04): 754-759

11 Stachowicz A, Siudut J, Suski M, et al. Optimization of quantitative proteomic analysis of clots generated from plasma of patients with venous thromboembolism. Clin Proteomics 2017;14:38

12 Wyatt AR, Yerbury JJ, Ecroyd H, Wilson MR. Extracellular chaperones and proteostasis. Annu Rev Biochem 2013;82:295-322

13 Gralnick HR, Givelber HM, Shainoff JR, Finlayson JS. Fibrinogen Bethesda: a congenital dysfibrinogenemia with delayed fibrinopeptide release. J Clin Invest 1971;50(09):1819-1830

14 Talens S, Malfliet JJ, van Hal PT, Leebeek FW, Rijken DC. Identification and characterization of $\alpha_{1}$-antitrypsin in fibrin clots. J Thromb Haemost 2013;11(07):1319-1328

15 Carter AM, Cymbalista CM, Spector TD, Grant PJ; EuroCLOT Investigators. Heritability of clot formation, morphology, and lysis: the EuroCLOT study. Arterioscler Thromb Vasc Biol 2007; 27(12):2783-2789

16 Vassar PS, Culling CF. Fluorescent stains, with special reference to amyloid and connective tissues. Arch Pathol 1959;68:487-498

17 Biancalana M, Koide S. Molecular mechanism of Thioflavin-T binding to amyloid fibrils. Biochim Biophys Acta 2010;1804 (07):1405-1412

18 Hartl FU, Bracher A, Hayer-Hartl M. Molecular chaperones in protein folding and proteostasis. Nature 2011;475(7356):324-332

19 Radcliffe R, Heinze T. Stimulation of tissue plasminogen activator by denatured proteins and fibrin clots: a possible additional role for plasminogen activator? Arch Biochem Biophys 1981;211(02): 750-761

20 Machovich R, Owen WG. Denatured proteins as cofactors for plasminogen activation. Arch Biochem Biophys 1997;344(02): 343-349
21 Kranenburg O, Bouma B, Kroon-Batenburg LM, et al. Tissue-type plasminogen activator is a multiligand cross-beta structure receptor. Curr Biol 2002;12(21):1833-1839

22 Beringer DX, Fischer MJ, Meeldijk JD, van Donselaar EG, de Mol NJ, Kroon-Batenburg LM. Tissue-type plasminogen activator binds to $\mathrm{A} \beta$ and AIAPP amyloid fibrils with multiple domains. Amyloid 2013;20(02):113-121

23 Constantinescu P, Brown RA, Wyatt AR, Ranson M, Wilson MR. Amorphous protein aggregates stimulate plasminogen activation, leading to release of cytotoxic fragments that are clients for extracellular chaperones. J Biol Chem 2017;292(35):14425-14437

24 Tang H, Fu Y, Zhan S, Luo Y. Alpha(E)C, the C-terminal extension of fibrinogen, has chaperone-like activity. Biochemistry 2009;48 (18):3967-3976

25 Wyatt AR, Wilson MR. Identification of human plasma proteins as major clients for the extracellular chaperone clusterin. J Biol Chem 2010;285(06):3532-3539

26 Wyatt AR, Kumita JR, Mifsud RW, Gooden CA, Wilson MR, Dobson $\mathrm{CM}$. Hypochlorite-induced structural modifications enhance the chaperone activity of human $\alpha 2$-macroglobulin. Proc Natl Acad Sci U S A 2014;111(20):E2081-E2090

27 Shacter E, Williams JA, Lim M, Levine RL. Differential susceptibility of plasma proteins to oxidative modification: examination by western blot immunoassay. Free Radic Biol Med 1994;17(05): 429-437

28 Gebbink MF. Tissue-type plasminogen activator-mediated plasminogen activation and contact activation, implications in and beyond haemostasis. J Thromb Haemost 2011;9(Suppl 1): 174-181

29 Longstaff C, Thelwell C, Williams SC, Silva MM, Szabó L, Kolev K. The interplay between tissue plasminogen activator domains and fibrin structures in the regulation of fibrinolysis: kinetic and microscopic studies. Blood 2011;117(02):661-668

30 Sakharov DV, Plow EF, Rijken DC. On the mechanism of the antifibrinolytic activity of plasma carboxypeptidase B. J Biol Chem 1997;272(22):14477-14482

31 Kell DB, Pretorius E. Proteins behaving badly. Substoichiometric molecular control and amplification of the initiation and nature of amyloid fibril formation: lessons from and for blood clotting. Prog Biophys Mol Biol 2017;123:16-41

32 Kell DB, Pretorius E. To what extent are the terminal stages of sepsis, septic shock, systemic inflammatory response syndrome, and multiple organ dysfunction syndrome actually driven by a prion/amyloid form of fibrin? Semin Thromb Hemost 2018;44 (03):224-238

33 Hudry-Clergeon G, Freyssinet JM, Torbet J, Marx J. Orientation of fibrin in strong magnetic fields. Ann N Y Acad Sci 1983; 408:380-387

34 Tsurupa G, Pechik I, Litvinov RI, et al. On the mechanism of $\alpha \mathrm{C}$ polymer formation in fibrin. Biochemistry 2012;51(12):2526-2538

35 Litvinov RI, Faizullin DA, Zuev YF, Weisel JW. The $\alpha$-helix to $\beta$ sheet transition in stretched and compressed hydrated fibrin clots. Biophys J 2012;103(05):1020-1027

36 Bhattacharyya J, Das KP. Molecular chaperone-like properties of an unfolded protein, alpha(s)-casein. J Biol Chem 1999;274(22): 15505-15509

37 Carrotta R, Canale C, Diaspro A, Trapani A, Biagio PL, Bulone D. Inhibiting effect of $\alpha(\mathrm{s} 1)$-casein on $A \beta(1-40)$ fibrillogenesis. Biochim Biophys Acta 2012;1820(02):124-132

38 Morgan PE, Treweek TM, Lindner RA, Price WE, Carver JA. Casein proteins as molecular chaperones. J Agric Food Chem 2005;53 (07):2670-2683

39 Chung DW, Chen J, Ling M, et al. High-density lipoprotein modulates thrombosis by preventing von Willebrand factor self-association and subsequent platelet adhesion. Blood 2016; 127(05):637-645 